\title{
Encystment probability and encystment rate: new terms to quantitatively describe formation of resting cysts in planktonic microbial populations
}

\author{
Kalle Olli ${ }^{1,2, *}$, Michael G. Neubert ${ }^{2}$, Donald M. Anderson ${ }^{2}$ \\ ${ }^{1}$ Biology Department, Woods Hole Oceanographic Institution, Woods Hole, Massachusetts 02543, USA \\ ${ }^{2}$ Institute of Botany and Ecology, University of Tartu, Lai 40, 51005 Tartu, Estonia
}

\begin{abstract}
Many dinoflagellates and other groups of phytoplankton have benthic resting cysts as part of their life cycle. Details of transitions among life cycle stages are few in the literature and often do not meet the rigorous standards needed for across-species generalisations or model parameterisation. One regularly reported but poorly understood aspect is the cyst yield, a quantitative characterisation of cyst formation in relation to the size of the vegetative population. The literature provides various formulae for calculating cyst yield; however, not all of these give biologically meaningful results. Here we introduce 2 new terms, 'encystment probability' and 'encystment rate' to quantitatively describe and easily calculate the average cyst formation potential of a population during a given time interval. Encystment probability $(\phi)$ is defined as the average probability of vegetative cells in a population switching to sexual reproduction (i.e. transforming into gametes which subsequently fuse to form planozygotes) as opposed to continuing vegetative growth through binary fission. Encystment rate $(\varepsilon)$ is an exponential loss rate from the vegetative population; it is the difference between the instantaneous growth rate of the population $(\mu)$ and the apparent increase of the vegetative cell population $(\mu-\varepsilon)$, provided no other losses take place. We propose a method of calculating encystment rate and encystment probability from readily available variables such as the number of vegetative cells at the beginning and end of a time interval and the number of resting cysts formed during the same period.
\end{abstract}

KEY WORDS: Life cycle $\cdot$ Encystment $\cdot$ Cyst yield $\cdot$ Population dynamics $\cdot$ Dinoflagellates

Resale or republication not permitted without written consent of the publisher

\section{INTRODUCTION}

Resting stage formation is a known feature in the life history of many algal groups, including diatoms (Smetacek 1985, McQuoid \& Hobson 1996), dinoflagellates (Dale 1983, Pfiester \& Anderson 1987, Head 1996), chrysophytes (Agbeti \& Smol 1995), green algae (Cain \& Trainor 1976, O'Kelly 1983), raphidophytes (Yoshimatsu 1987, Nakamura et al. 1990), haptophytes (Green et al. 1982), cyanobacteria (Li et al. 1997, van Dok \& Hart 1997) and euglenids (Triemer 1980, Olli 1996). Resting cysts of dinoflagellates are significant in initiating red tides (Anderson et al. 1983) and the switch from asexual to sexual reproduction can be a major factor in the decline of blooms (Anderson et al. 1983, Heiskanen 1993, Kremp \& Heiskanen 1999).
Most laboratory culture experiments suggest that dinoflagellate sexuality is induced under the relatively specific conditions of limitation of nitrogen or phosphorus (von Stosch 1973, Anderson et al. 1984, Coats et al. 1984, Binder \& Anderson 1987, Blackburn et al. 1989, Doucette et al. 1989, Park \& Hayashi 1993), although many field studies do not support this hypothesis (Wall et al. 1970, Anderson et al. 1983, Kremp \& Heiskanen 1999). Cyst formation (encystment) in dinoflagellates is not a simple, single-step process. It involves different steps and processes, many of which are poorly described and understood. While the literature provides some insight into factors inducing gamete formation, survival time of planozygotes and factors affecting encystment, we lack even basic understanding on, for example, the proportion of the population forming 
gametes, mating duration and mating success of gametes, survival time of gametes, swimming/sinking behaviour and speed of gametes and planozygotes, proportion of planozygotes that encyst, and time taken to encyst (Lewis 2002). To facilitate comparison and modelling across the species, we need consensus on terminology and standardisation of methods.

An important biological parameter that has been reported regularly in the literature, but is poorly characterised in laboratory experiments and even more so in field studies, is encystment success or cyst yield (the proportion of the vegetative population that forms cysts). High variability in the cyst yield has been one of the unresolved issues in dinoflagellate life cycles. Most laboratory experiments have shown that only a relatively small fraction of the dinoflagellate population forms cysts (Dale 1983). In many cases special nutrientdeplete 'encystment media' have been used to produce resting cysts of dinoflagellates, but final encystment percentages remain modest, usually < 40\% (Dale 1983, Anderson et al. 1984, Anderson \& Lindquist 1985, Binder \& Anderson 1987, Lirdwitayaprasit et al. 1990, Park \& Hayashi 1993, Montresor \& Marino 1996). Recently, cyst yields up to $100 \%$ have been reported (Sgrosso et al. 2001, Olli \& Anderson 2002). However, in the literature one can find more than 1 formula for calculating cyst yield (using data on vegetative cell population and cysts produced), and some authors do not report how they have calculated their data.

Hitherto, 2 different approaches have been used to quantitatively relate encystment to vegetative population size. First, vegetative cells and cysts from a culture sample are separately quantified at any given time. A simple proportion of cysts to vegetative cells has been used (Ichimi et al. 2001). A more realistic ratio of twice the number of cysts (assuming that 2 cells fuse to form a cyst) divided by twice the number of cysts plus the number of vegetative cells $\left(2 \mathrm{~N}_{\text {cysts }} /\left[2 \mathrm{~N}_{\text {cysts }}+\mathrm{N}_{\text {veg. cells }}\right]\right)$ is used as a quantitative estimate of encystment success (Coats et al. 1984, Anderson \& Lindquist 1985, Binder \& Anderson 1987, Park \& Hayashi 1993). This ratio has a range between 0 and 1 (or 0 to $100 \%$ ) which eases interpretation. However, the interpretation of this ratio as the percentage of cells which forms cysts (Park \& Hayashi 1993) is not correct (unless all the vegetative cells have successfully turned into cysts). A correct interpretation of the above ratio is the percentage of the population consisting of cysts (Coats et al. 1984). Because it involves cysts formed during previous time intervals, it is not an indicator of the encystment process at a given moment in time, and gives no information on the proportion of the vegetative population that forms cysts. In another approach, the total cumulative cyst yield has been related to the peak of the vegetative cell population (Anderson et al. 1984, 1985, Kremp \& Heiskanen 1999) to quantitatively assess the percentage of the total population which encysted successfully. Even when the peak of the vegetative cell population has been correctly estimated, to conform with the above interpretation the index requires that no cysts are formed before and no growth takes place after the vegetative cell maximum. Generally, we cannot assume these requirements to be met. If cyst production and vegetative growth proceed simultaneously, the total cumulative cyst yield can exceed many times the peak of the vegetative cell population size (Olli \& Anderson 2002), invalidating the biological interpretation of the ratio as intended.

In this paper we propose 2 new terms, 'encystment rate' and 'encystment probability', to quantitatively describe the encystment success of a population at any given time interval. Encystment rate $(\varepsilon)$ is defined as the instantaneous rate at which new cysts are produced in a population, analagous to the instantaneous growth rate $(\mu)$ which describes the exponential increase of a microbial population in the case of no loss rates.

\section{MATERIALS AND METHODS}

For the sake of simplicity we consider an exponentially growing population in which encystment is the only loss from the vegetative population, and there are no true losses from the total population. The general calculation below assumes that each cyst is formed by 1 vegetative cell, and can be used directly when cyst formation does not involve the fusion of 2 gametes. When it does, as in the case of sexual hypnozygotes of dinoflagellates, the simplest modification would be to use twice the amount of actual resting cysts in the calculations. To calculate the mean encystment rate during an arbitrary time interval we need only 5 easily obtainable parameters: (1) $\Delta t$, the duration of the time interval $(t, t+\Delta t) ;(2) N_{t}$, the concentration of vegetative cells at the beginning of the period; (3) $N_{t+\Delta t}$, the concentration of vegetative cells at the end of the period; (4) $C_{t}$, the number of cysts at the beginning of the period; and (5) $C_{t+\Delta t}$ the number of cysts at the end of the period.

The amount of new cysts produced during the time interval is obtained as $C_{t+\Delta t}-C_{t}$.

The unknown parameters are $\mu$ (instantaneous growth rate of the population) and $\varepsilon$ (encystment rate of the population).

We assume a simple model in which the vegetative population grows exponentially through binary fission with a specific growth rate $\mu$. In the absence of encystment, the rate of change of the vegetative population is proportional to its size: 


$$
\frac{\mathrm{d} N}{\mathrm{~d} t}=\mu N
$$

With encystment, however, a certain number of vegetative cells are removed from the actively growing population. The rate of change of the vegetative population is then reduced by the encystment rate and Eq. (1) modified to:

$$
\frac{\mathrm{d} N}{\mathrm{~d} t}=(\mu-\varepsilon) N
$$

Cysts are produced from the vegetative population only. We ignore the more complicated possibility of division cysts here, as in the case of temporary cysts of Alexandrium taylori (Garcés et al. 2002). Thus the accumulation rate of cysts is also proportional to the vegetative population size:

$$
\frac{\mathrm{d} C}{\mathrm{~d} t}=\varepsilon N
$$

and

$$
\frac{\mathrm{d} C}{\mathrm{~d} N}=\frac{\varepsilon}{\mu-\varepsilon}
$$

The denominator on the right side of the above equation $(\mu-\varepsilon)$ is the increase rate of the vegetative population and can be readily calculated from the available data:

$$
\mu-\varepsilon \approx \frac{\ln \left(\frac{N_{t+\Delta t}}{N_{t}}\right)}{\Delta t}
$$

Now we are ready to calculate the encystment rate by solving Eq. (4) for $\varepsilon$ :

$$
\varepsilon=\frac{\mathrm{d} C}{\mathrm{~d} N}(\mu-\varepsilon) \approx\left(\frac{C_{t+\Delta t}-C_{t}}{N_{t+\Delta t}-N_{t}}\right)(\mu-\varepsilon)
$$

The growth rate of the population follows as:

$$
\mu=(\mu-\varepsilon)+\varepsilon
$$

Thus, encystment rate $(\varepsilon)$ can be seen as the rate by which the instantaneous growth of the population $(\mu)$ exceeds the increase rate $(\mu-\varepsilon)$ of the vegetative population. The growth and encystment rates of the population enable us to calculate the number of cysts which accumulate during a certain time period:

$$
C_{t+\Delta t}-C_{t}=\frac{\varepsilon N_{t}}{\mu-\varepsilon}\left[\mathrm{e}^{(\mu-\varepsilon) \Delta t}-1\right]
$$

During each cell cycle, the daughter cells either continue to divide through binary fission or switch to sexual reproduction. The encystment probability $(\phi)$ is the probability that any particular vegetative cell will switch to sexual reproduction (i.e. the cell transforms into a gamete, fuses with another gamete, forms a planozygote and finally a non-motile hypnozygote). Encystment probability can be calculated as:

$$
\phi=\frac{\varepsilon}{\mu+\varepsilon}
$$

In the case of sexually reproducing dinoflagellates or other micro-organisms where 2 vegetative cells or gametes are needed to form a cysts, Eq. (6) modifies to:

$$
\varepsilon=\frac{2 \mathrm{~d} C}{\mathrm{~d} N}(\mu-\varepsilon) \approx\left[\frac{2\left(C_{t+\Delta t}-C_{t}\right)}{N_{t+\Delta t}-N_{t}}\right](\mu-\varepsilon)
$$

The above calculations can be exemplified using previously published data from a laboratory experiment with a monospecific culture of a coastal cystproducing dinoflagellate Scrippsiella lachrymosa (Olli \& Anderson 2002). In that experiment the population dynamics and life cycle change of $S$. lachrymosa were followed for a period of $52 \mathrm{~d}$ in 2 sets of test tubes filled with $10 \mathrm{ml}$ of f/2-Si and f/4-Si medium (Guillard \& Ryther 1962); 2 sets of 24 tubes were filled with either medium and inoculated with cells in exponential growth phase. At certain time intervals, 3 tubes from both sets were sacrificed at random and the cells and cysts were quantified. Consequently, all the samples represented independent estimates of the average population development in all the test tubes within the treatment. This differs from repeated-measures design, whereby a population in the same batch culture would be sampled over a period of time. We rejected the repeated-measures design because harvesting cysts involved a few seconds of sonication at low power (Branson Ultrasonic Model 250) to agitate the cysts that had settled to the bottom of the tube. Frequent disturbances could potentially have had adverse effects on dinoflagellate population development, which we wanted to avoid. The trade-off with the present independent-measures design involved additional errors and variability caused by the differences between the tubes. The variability between the 3 replicates describes the differences in the population growth in individual tubes.

\section{RESULTS AND DISCUSSION}

Fig. 1 shows the dynamics of vegetative cells and accumulation of cysts in the test tubes; the numerical data and results of the calculations, applying Eq. (10) as appropriate for dinoflagellates, are given in Table 1. The exponential growth rate followed the usual pattern, with an initial lag phase followed by an increase during the log phase. Thereafter, the vegetative population density decreased abruptly as a consequence of massive encystment. Some cysts were formed already in the early phase of the population development, but intensive cyst formation took place after Day 16 in growth medium f/4 or Day 24 in f/2. 


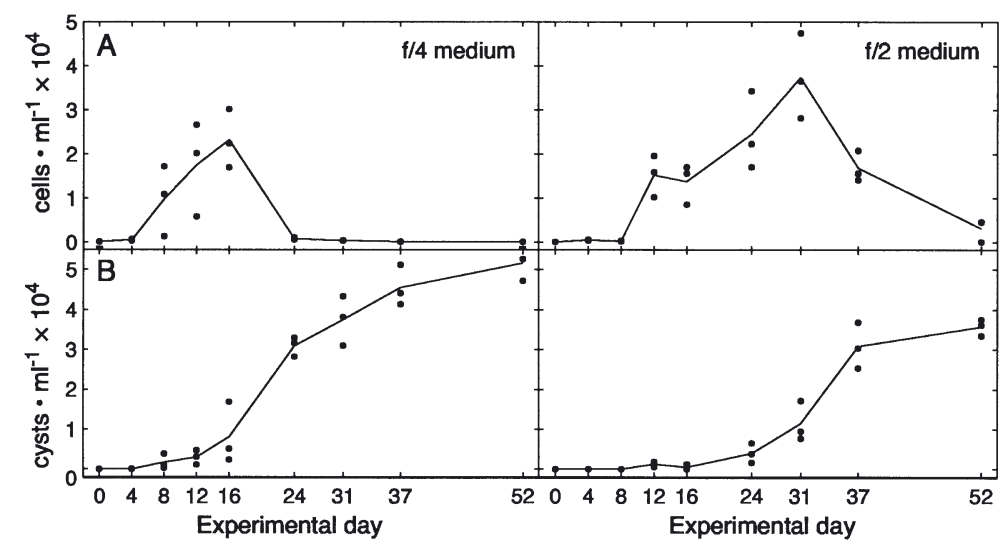

Fig. 1. Scrippsiella lachrymosa. (A) dynamics of vegetative cells; (B) accumulation of cysts in test tubes filled with $\mathrm{f} / 4$ and $\mathrm{f} / 2$ media. Data points represent concentrations in 3 individual tubes and line is mean of the 3 values. Note high variability in data caused by differences in population development between test tubes. (Data from Olli \& Anderson 2002)

For the vegetative cell population, encystment is a loss rate which has to be compensated for by an even higher growth rate if the vegetative population is to increase in size. The model does not incorporate any loss rates from the total population. Losses from the vegetative population should be compensated by corresponding increases in the cyst population. Apart from experimental and counting errors, it is safe to assume that in batch culture we had no losses from the vegetative population other than cyst formation. This is not the case in natural field conditions. Cells are lost due to viral lysis, zooplankton grazing, advection, etc. If the magnitudes of these losses are not known, then we have more unknown parameters than equations and there must be an infinite number of solutions to satisfy the equations. However, if there are good reasons to assume that loss rates are insignificant, the model can give a good estimate of encystment rate and probability under natural conditions. The calculations can be applied to several other groups of organisms with microbial-type growth dynamics and loss to an accumulating, non-growing fraction of the population. The non-growing fraction can be dormant cells or dead organisms, provided their accumulation can be reliably quantified during a time interval. Indeed, the formula is applicable to time-course data only, with 2 data points as a minimum to calculate 1 rate estimate. The rate and probability estimates are dynamic properties of the population at any given time, determined by internal and external factors. They are fundamentally different from the widely used ratio of cysts to total population $\left(2 \mathrm{~N}_{\text {cysts }} /\left[2 \mathrm{~N}_{\text {cysts }}+\mathrm{N}_{\text {veg. cells }}\right]\right)$ which, however, remains the preferred expression of cyst yield when only 1 data point is available.

In our experiment, estimates of the total population size decreased during 3 time intervals in the $\mathrm{f} / 2$ treatment (Days 8, 16, 52; see Table 1), where the model does not give a solution. This decrease was most probably an artifact caused by differences in the population development between individual tubes and/or counting errors. If cyst formation is the sole loss rate from a vegetative population, then any decrease the vegetative cell number must be compensated by an increase in cyst numbers. If the increase in cyst numbers is less than the decrease in vegetative population, we are faced with obvious experimental or counting errors and the calculations do not give biologically meaningful results. However, if gametes fuse but fail to form cysts (Anderson et al. 1984, Coats et al. 1984, Anderson \& Lindquist 1985), the vegetative population size will decrease without accompanying cyst production. This was not the case in our example. Encystment of Scripp-

Table 1. Scrippsiella lachrymosa. Summary of the population dynamics experiment in f/4 and f/2 media (Olli \& Anderson 2002). Day: day of experiment; Duration: time interval (d); Cells: concentration of vegetative cells and resting cysts $\left(\mathrm{ml}^{-1}\right)_{i} \varepsilon$ : mean exponential encystment rate calculated with Eq (10); $\mu$ : growth rate; $\phi$ : encystment probability during time interval. Day 0 represents inoculum size; cell and cyst counts are means of 3 replicate samples (see Fig. 1); na (not applicable) represents cases when total population size (vegetative cells $+2 \times$ cysts) decreased during time interval

\begin{tabular}{|c|c|c|c|c|c|c|c|c|c|c|c|}
\hline Day & Duration & Cells & Cysts & $\begin{array}{c}\varepsilon \\
\mathrm{f} / 4\end{array}$ & $\mu$ & $\phi$ & Cells & Cysts & $\begin{array}{c}\varepsilon \\
\mathrm{f} / 2\end{array}$ & $\mu$ & $\phi$ \\
\hline 0 & & 114 & 0 & & & & 67 & 0 & & & \\
\hline 4 & 4 & 501 & 31 & 0.06 & 0.43 & 0.12 & 489 & 5 & 0.01 & 0.51 & 0.023 \\
\hline 8 & 4 & 9795 & 1722 & 0.27 & 1.01 & 0.21 & 161 & 14 & na & na & na \\
\hline 12 & 4 & 17542 & 2965 & 0.05 & 0.19 & 0.20 & 15245 & 1279 & 0.19 & 1.33 & 0.126 \\
\hline 16 & 4 & 23186 & 8118 & 0.13 & 0.20 & 0.39 & 13759 & 500 & na & na & na \\
\hline 24 & 8 & 764 & 30920 & 0.87 & 0.44 & 0.66 & 24571 & 3989 & 0.05 & 0.12 & 0.282 \\
\hline 31 & 7 & 366 & 37511 & 3.48 & 3.38 & 0.51 & 37420 & 11476 & 0.07 & 0.13 & 0.350 \\
\hline 37 & 6 & 122 & 45570 & 12.10 & 11.91 & 0.50 & 16856 & 30858 & 0.25 & 0.12 & 0.680 \\
\hline 52 & 15 & 84 & 51689 & 8.01 & 7.99 & 0.50 & 3098 & 35754 & na & na & na \\
\hline
\end{tabular}


siella lachrymose was always fast $(<24 \mathrm{~h}$, see Olli \& Anderson 2002) and planozygotes were never observed in large numbers. In the f/4 treatment the requirement for lack of total population decrease was fulfilled. However, the growth rate reached exceedingly high values in the latter part of the experiment. From Fig. 1 it appears that in f/4 medium the time interval between Days 16 and 24 represented almost a total disappearance of vegetative cells accompanied by extensive cyst formation. From Day 24 onwards, the population consisted almost totally of resting cysts. It became increasingly difficult to find adequate numbers of vegetative cells in the samples to assure satisfactory counting statistics. The amount of vegetative cells may therefore have been underestimated. At the same time, the concentration of cysts continued to increase. If the increase in cyst number is larger than the decrease in the vegetative population, the model adjusts the growth and encystment rates to match the vegetative and cyst population sizes at the end of the period. In our case, by forcing an exceedingly high growth rate for the few remaining vegetative cells. The reasons for the discrepancy between the increase in cyst numbers and the relatively small vegetative population size are not clear. We believe it was partly due to the counting statistics of the vegetative cells, while the increasing cyst numbers could partly be caused by variability in the population size and encystment success in different tubes. Our experimental design, (based on sampling of independent test tubes several weeks after inoculation) introduced variability caused by differences in the population development between the tubes. This led to uncertainties in the estimates of total population (all the tubes) development, and demonstrates the quality requirements of the data, which should be accounted for when planning sampling. Inconsistencies in the data will not pass the model. A biological mechanism cannot be excluded as a partial explanation of the elevated growth rate in $\mathrm{f} / 4$ medium. Cetta \& Anderson (1990) found that gametes of Gyrodinium uncatenum were formed by a series of rapid divisions at rates far exceeding those for normal vegetative division. This conforms with the findings of Coats et al. (1984), based on protagol staining, that gametes of $G$. uncatenum were formed by 2 rapid divisions in $\leq 24 \mathrm{~h}$. Yet the extremly high growth rates of 12 and $8 \mathrm{~d}^{-1}$ during the last 2 time intervals (Table 1) are biologically unrealistic, and are probably the result of the chosen experimental design and counting statistics of the few remaining vegetative cells.

Encystment probability directly describes the proportion of vegetative population that switches to sexual reproduction at any given time. It is a property of the population, with clear biological meaning and is easy to interpret. Encystment probability is 0.5 when encystment rate equals growth rate. In this situation the vegetative population ceases to increase or decrease irrespective of the numeric value of the growth rate. All the population increase, whether $\mu$ is high or low, is channelled to the cyst pool. When encystment rate exceeds growth rate, the vegetative population size starts to decrease as $\mu-\varepsilon$ becomes negative, and the encystment probability exceeds 0.5 . When the encystment rate approaches the decrease rate of the vegetative population, the encystment probability approaches unity. In this case, binary fission ceases in the population and the next cell cycle event is fusion between gametes. If no cysts are formed, the number of vegetative cells has to be at least constant (assuming no loss rates). If it increases, the growth rate equals the value calculated from the net increase of the vegetative population size.

A potential source of error can be the prolonged gamete and/or planozygote stage in the life cycle. First, gametes and planozygotes form a non-dividing fraction of the motile population. Thus a large gamete and planozygote fraction can cause underestimation of the growth rate of the vegetative population. Second, as noted above, planozygote formation decreases the size of the motile population due to the fusion of 2 gametes. When planozygotes are not morphologically easily recognized, are formed at a high rate, and have a long life span before encystment, it can lead to an apparent but false decrease in the total population size, which is not accounted for by the model. The duration of gamete and planozygote life cycle stages is generally not known. In many species gametes are not easily distinguished from vegetative cells, and it seems plausible that gametogenesis may merely be effected by an internal switch within vegetative cells (e.g. Coats et al. 1984). In a few cases, when gametes and planozygotes are readily distinguishable from vegetative cells, the time lag between first appearance of gametes, planozygotes and cysts can be used as a proxy (Anderson et al. 1983, Kremp \& Heiskanen 1999). Times taken by planozygotes to proceed to encystment are reported to be in the order of 1 to 2 wk (Anderson et al. 1983, Anderson \& Lindquist 1985, Blackburn et al. 1989) but, depending on species, the process can take also less than $1 \mathrm{~d}$ (Olli \& Anderson 2002). It is advisable that these potential sources of error, which can largely be species-specific and can vary according to the environment, should be considered when estimating encystment rates.

Acknowledgements. This research was supported in part by NOAA Grant NA96OP0099 and NSF Grant OCE-9808173 (D.M.A.), by the Estonian Science Foundation (ETF 3329, 5262), the European Commission (EKV3-2001-00050; 003875), and personal grants from NSF/NATO (DGE9804544), Fulbright Foundation, and the Postdoctoral Program of the Woods Hole Oceanographic Institution (K.O.). 
This effort was supported by the US ECOHAB Program sponsored by NOAA, the US EPA, NSF, NASA and ONR. We are grateful to the constructive comments of the 3 anonymous reviewers. This is Contribution No. 11094 from the Woods Hole Oceanographic Institution, and Contribution No. 95 from the ECOHAB program.

\section{LITERATURE CITED}

Agbeti MD, Smol JP (1995) Chrysophyte population and encystment patterns in two Canadian lakes. J Phycol 31: $70-78$

Anderson DM, Lindquist NL (1985) Time-course measurements of phosphorus depletion and cyst formation in the dinoflagellate Gonyaulax tamarensis Lebour. J Exp Mar Biol Ecol 86:1-13

Anderson DM, Chisholm SW, Watras CJ (1983) Importance of life cycle events in the population dynamics of Gonyaulax tamarensis. Mar Biol 76:179-189

Anderson DM, Kulis DM, Binder BJ (1984) Sexuality and cyst formation in the dinoflagellate Gonyaulax tamarensis: cyst yield in batch cultures. J Phycol 20:418-425

Anderson DM, Coats DW, Tyler MA (1985) Encystment of the dinoflagellate Gyrodinium uncatenum: temperature and nutrient effects. J Phycol 21:200-206

Binder BJ, Anderson DM (1987) Physiological and environmental control of germination in Scrippsiella trochoidea (Dinophyceae) resting cysts. J Phycol 23:99-107

Blackburn SI, Hallegraeff GM, Bolch CHJ (1989) Vegetative reproduction and sexual life cycle of the toxic dinoflagellate Gymnodinium catenatum from Tasmania, Australia. J Phycol 25:577-590

Cain JR, Trainor FR (1976) Regulation of gametogenesis in Scenedesmus obliquus (Chlorophyceae). J Phycol 12: 383-390

Cetta CM, Anderson DM (1990) Cell cycle studies of the dinoflagellates Gonyaulax polyedra Stein and Gyrodinium uncatenatum Hulburt during sexual and asexual reproduction. J Exp Mar Biol Ecol 135:69-84

Coats DW, Tyler MA, Anderson DM (1984) Sexual processes in the life cycle of Gyrodinium uncatenum (Dinophyceae): a morphogenetic overview. J Phycol 20:351-361

Dale B (1983) Dinoflagellate resting cysts: 'benthic plankton'. In: Frixell G (ed) Survival strategies of the algae. Cambridge University Press, Cambridge, p 69-136

Doucette GJ, Cembella AD, Boyer GL (1989) Cyst formation in the red tide dinoflagellate Alexandrium tamarense (Dinophyceae): effects of iron stress. J Phycol 25:721-731

Garcés E, Masó M, Camp J (2002) Role of temporary cysts in the population dynamics of Alexandrium taylori (Dinophyceae). J Plankton Res 24:681-686

Green JC, Hibberd DJ, Pienaar RN (1982) The taxonomy of Prymnesium (Prymnesiophyceae) including a description of a new cosmopolitan species, $P$. patillifera sp. nov., and further observations on P. parvum N. carter. Br Phycol J $17: 363-382$

Guillard RRL, Ryther JH (1962) Studies of marine planktonic diatoms. I. Cyclotella nana Hustedt and Detonula confervaceae (Cleve) Gran. Can J Microbiol 8:229-239

Head MJ (1996) Modern dinoflagellate cysts and their biological affinities. In: Jansonius J, McGregor DC (eds) Palynology: principles and applications, Vol 3. Almerican Association of Stratigraphic Palynologists Foundation, College Station, TX, p 1197-1248

Heiskanen AS (1993) Mass encystment and sinking of dino- flagellates during a spring bloom. Mar Biol 116:161-167

Ichimi K, Yamasaki M, Okumura Y, Susuki T (2001) The growth and cyst formation of a toxic dinoflagellate Alexandrium tamarense, at low water temperatures in northeastern Japan. J Exp Mar Biol Ecol 261:17-29

Kremp A, Heiskanen AS (1999) Sexuality and cyst formation of the spring-bloom dinoflagellate Scrippsiella hangoei in the coastal northern Baltic Sea. Mar Biol 134:771-777

Lewis J (2002) Data on encystment and excystment rates in dinoflagellates. In: Garcés E, Zingone A, Montresor M, Reguera B, Dale B (eds) LIFEHAB: life histories of microalgal species causing harmful algal blooms, Vol 12. European Commission, Luxembourg, p 49-52

Li R, Watanabe M, Watanabe MM (1997) Akinete formation in planktonic Anabaena spp. (Cyanobacteria) by treatment with low temperature. J Phycol 33:576-584

Lirdwitayaprasit T, Okaichi T, Montani S, Ochi T, Anderson DM (1990) Changes in cell chemical composition during the life cycle of Scrippsiella trochoidea (Dinophyceae). J Phycol 26:299-306

McQuoid MR, Hobson LA (1996) Diatom resting stages. J Phycol 32:889-902

Montresor M, Marino D (1996) Modulating effect of cold-dark storage on excystment in Alexandrium pseudogonyaulax (Dinophyceae). Mar Biol 127:55-60

Nakamura Y, Umemori T, Watanabe M, Kulis DM, Anderson DM (1990) Encystment of Chattonella antiqua in laboratory cultures. J Oceanogr Soc Jpn 46:35-43

O'Kelly JC (1983) Environmental factors and sexual expression in Chlorococcum echinozygotum (Chlorophyceae). J Phycol 19:57-64

Olli K (1996) Resting cyst formation of Eutreptiella gymnastica (Euglenophyceae) in the northern coastal Baltic Sea. J Phycol 32:535-542

Olli K, Anderson DM (2002) High encystment success of the dinoflagellate Scrippsiella cf. lachrymosa in culture experiments. J Phycol 18:145-156

Park HD, Hayashi H (1993) Role of encystment and excystment of Peridinium bipes f. occulatum (Dinophyceae) in freshwater red tides in lake Kizaki, Japan. J Phycol 29: 435-441

Pfiester LA, Anderson DM (1987) Dinoflagellate reproduction. In: Taylor FJR (ed) The biology of dinoflagellates, Vol 21. Blackwell Scientific Publications, Oxford, p 611-648

Sgrosso S, Esposito F, Montresor M (2001) Temperature and daylength regulate encystment in calcareous cyst-forming dinoflagellates. Mar Ecol Prog Ser 211:77-87

Smetacek V (1985) Role of sinking in diatom life-history cycles: ecological, evolutionary and geological significance. Mar Biol 84:239-251

Triemer RE (1980) Role of golgi apparatus in mucilage production and cyst formation in Euglena gracilis (Euglenophyceae). J Phycol 16:46-52

van Dok W, Hart BT (1997) Akinete germination in Anabaena circinalis (Cyanophyta). J Phycol 33:12-17

von Stosch HA (1973) Observations on vegetative reproduction and sexual life cycle of two freshwater dinoflagellates, Gymnodinium pseudopalustre Schiller and Woloszynskia apiculata sp. nov. Br Phycol J 8:105-134

Wall D, Guillard RRL, Dale B, Swift E, Watabe N (1970) Calcite resting cysts in Peridinium trochoideum (Stein) Lemmermann, an autotrophic marine dinoflagellate. Phycologia 9:151-156

Yoshimatsu S (1987) The cysts of Fibrocapsa japonica (Raphidiophyceae) found in bottom sediment in Harima-Nada, Eastern Inland Sea of Japan. Bull Plankton Soc Jpn 34:25-31 